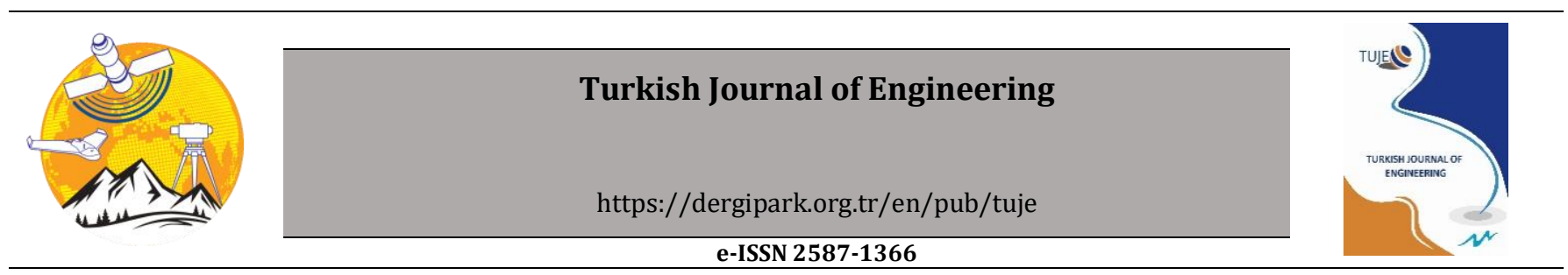

\title{
Wind power plant layout optimization using particle swarm optimization
}

\author{
İbrahim Çelik ${ }^{* 1}$, Ceyhun Yıldız ${ }^{1}$, Mustafa Şekkeli 2 () \\ ${ }_{1}^{1}$ Kahramanmaraş İstiklal University, Elbistan Vocational School, Department of Electricity, Kahramanmaraş, Turkey \\ 2Kahramanmaraş Sütçü İmam University, Engineering Faculty, Electrical and Electronics Engineering Department, Kahramanmaraș, \\ Turkey
}

\author{
Keywords \\ Micro-siting \\ Wind power plant \\ Particle swarm optimization \\ WAsP \\ Weibull distribution
}

\begin{abstract}
The use of wind energy has rapidly increased in recent years. In parallel with this rapid increase, Wind Power Plant (WPP) installation has become an important research topic. The selection of wind turbine location in WPP installation effects turbine output power. If the appropriate turbine position is not selected, the total generation of WPP is decreased. The purpose of this study was to determine the locations that wind turbines can achieve the highest energy generation. In this study, an optimization model was proposed to achieve the best WPP layout. In the first stage, field data and Wind Atlas Analysis and Application Program (WAsP) software were used to obtain wind speed distributions in the region where the WPP will be installed. . These distributions were used in the developed optimization model in MATLAB. The actual power curve of a wind turbine was used in the model to calculate energy generation. In the second stage, the locations of the wind turbine were determined by particle swarm optimization (PSO) method. In the final stage, the results of developed MATLAB model were compared with WASP to check accuracy. The difference between MATLAB model and WAsP software was found as $0.04 \%$. This result showed that this model performed a calculation with acceptable accuracy. In addition, it was seen that wind turbines were located to the high wind velocity regions with the solution of the developed optimization model.
\end{abstract}

\section{INTRODUCTION}

In recent years, there has been a rapid development in the installation of wind power plants (WPP) all around the world. There has been a lot of studies about wind energy and WPP installation (Sekkeli et al. 2015a; Feng and Shen 2015; Long and Zhang 2015; Sekkeli et al. 2015b; Karadöl et al. 2017; Abdelsalam and El-Shorbagy 2018; Yang et al. 2019; Celik et al. 2019). Due to this rapid increase in WPP installation, wind turbines micro-siting has been an important research topic. Because turbine positions have an important effect on the output power of the wind turbines.

In literature, it is seen that wind turbine micro-siting has been considered as an optimization problem in WPP installation ( Turner et al. 2014; Chen et al. 2015; Gao et al. 2015; Parada et al. 2017; Celik et al. 2018; Wang et al. 2018; Sun et al. 2019). Generally, in modeling studies to solve the optimization problem has been used to the theoretical wind speed -power curve (Mosetti et al. 1994; Grady et al. 2005; Marmidis et al. 2008; Wan et al. 2010;
Kusiak and Song 2010; Emami and Noghreh 2010). Only a few studies have been used the experimental wind speed - power curve (Garcia- Bustamante et al. 2009; González et al. 2010; González et al. 2011; Pagnini et al. 2015). Also, the theoretical climate data has been used in models (Changshui et al. 2011; Chen et al. 2013; Brusca et al. 2014; Yang et al. 2015; Chen et al. 2016).

In this study, an experimental turbine power curve was used to obtain more realistic results. Also, field data and industry standard WAsP software were used to develop optimization model. The analyzed WPP installation area was in southern region of Argentine. Wind speed and direction data were site measurements of installation area.

After modeling the wind distributions of WPP installation area and wind turbines power generations, the developed model was solved by using Particle Swarm Optimization (PSO). PSO method has been one of the most popular methods using to determine the location of the wind turbine (Pookpunt and Ongsakul 2013; Hou et 
al. 2015; Pookpunt and Ongsakul 2016; Song et al. 2018). This method provides the highest possible benefit from the wind energy.

This study aims to develop an optimization model for WPP installation. For this purpose, the optimization model was developed and solved in MATLAB environment. The solution of this model was obtained by the PSO method. This solution was the locations of the wind turbines, which could generate the highest power output. The detailed description of the model was given in Section 2. The PSO method was given in Section 3. Finally, the model outputs and WAsP outputs were compared to check the accuracy of the developed model.

The contribution of this study to the literature has been the use of the PSO, which is an effective method, with real field data and a real turbine power curve in WPP layout optimization.

This study consists of five sections. In the first section, the subject was generally explained. Also, used method and the summary of the literature was mentioned in this section. In the second section the theoretical background of the developed optimization model. In the section three, PSO method was described. In the fourth section, the field data and the wind turbine were presented. In the fifth section, the results of MATLAB model which was solved with the PSO method and the WAsP results of a commercial software were compared. In the last section, the results were evaluated.

\section{THEORETICAL BACKGROUND OF OPTIMIZATION MODEL}

In this study, an optimization model is developed to determine the highest generation locations of the wind turbines in a WPP installation. The constraints of model are given from the eq. (1) to (4). These constraints prevent to site the wind turbines to the same locations. The objective function is presented in eq. (5). In here, CRES and GRES represent the annual cost of a WPP and the annual total generation of a WPP.

$$
\begin{aligned}
& 1 \leq i \leq 10 \forall i \in N \\
& 1 \leq j \leq 10 \forall j \in N \\
& i \neq j \forall j, i \in N^{+} \\
& f_{\text {obj }}=\left(\frac{G_{W P P}}{C_{W P P}}\right)
\end{aligned}
$$$$
\sqrt{\left(X_{j}-X_{i}\right)^{2}+\left(Y_{j}-Y_{i}\right)^{2}}>0
$$

The objective function is aimed to maximize the annual total generation. The number of wind turbines is kept constant in the developed model. Therefore, only increasing the annual total generation is meaningful in the objective function

The annual total generation of WPP is calculated using eq. (6). In this equation, $\mathrm{N}_{\mathrm{z}}$ is the number of the wind turbines. The cut in wind speed $\left(\mathrm{V}_{\mathrm{ci}}\right)$ is the wind speed that the turbine begins to generate power. The cutout wind speed $\left(\mathrm{V}_{\text {co }}\right)$ is maximum wind speed that the turbine can generate power. Besides, $\mathrm{P}\left(\mathrm{V}_{\mathrm{i}}\right)$ refers to wind turbine power curve. And $\mathrm{f}\left(\mathrm{V}_{\mathrm{i}}\right)$ is Weibull probability density function

$G_{W P P}=\sum_{i=1}^{i=N_{z}} 8760\left[\int_{V_{c i}}^{V_{c o}} f\left(V_{i}\right) P\left(V_{i}\right) d v_{i}\right]$

The 2-parameter Weibull probability density function is shown in eq. (7). The $\mathrm{k}$ and $\mathrm{A}$ are shape and scale parameters respectively (Celik et al. 2018). These parameters are obtained from WAsP software.

$f\left(v_{i}\right)=(k / A)\left(v_{i} / A\right)^{k-1} e^{-\left(\frac{v_{i}}{A}\right)}$

In this study, Eq. 8 is used to calculate the annual cost of the WPP in objective function (Gao et al. 2015).

$\mathrm{C}_{\mathrm{WPP}}=\mathrm{N}_{\mathrm{z}}\left(\frac{2}{3}+\frac{1}{3} \mathrm{e}^{-0.00174 \mathrm{~N}_{\mathrm{z}}^{2}}\right)$

This developed optimization model is solved and optimum settlement locations for wind turbines are found. PSO method is used in this study to solve the model.

\section{PSO METHOD}

PSO method, which inspired by the movement of the bird flocks, was developed by Kennedy and Eberhart in 1995. In this method, the initial population is created by random solutions. Then, to obtain the optimum solution this created population is updated from generation to generation. The stopping criteria of the search process is exceeding the number of generations. (Kennedy and Eberhart 1995; Engelbrecht 2005).

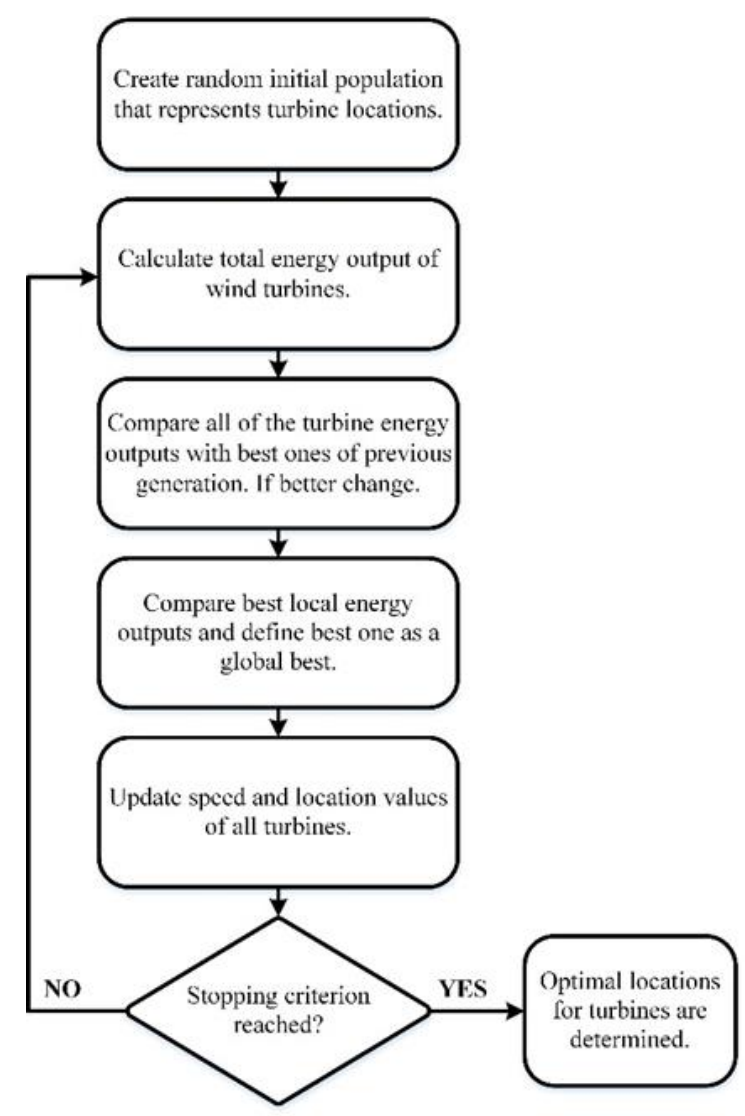

Figure 1. PSO method operation steps 
The detailed explanation of the PSO method steps are given in Fig.1.

\section{FIELD DATA AND WPP INSTALLATION AREA}

The installation area of WPP is in the southern of Argentina. This area is shown in Fig. 2. The field data for this area are obtained from WAsP library. This field data are used in all calculations of the developed model.

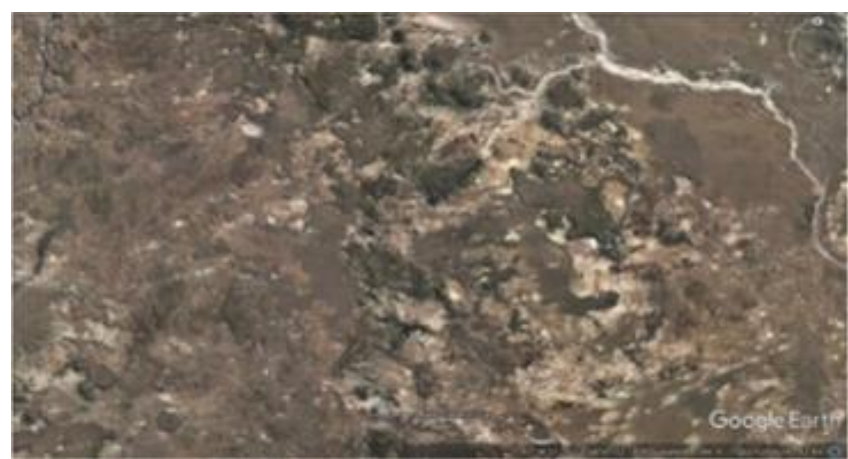

Figure 2. WPP installation area

The average wind velocity map of the installation area is given at the Figure 3. This map is divided into 20 equal parts by accepting the horizontal axis $(\mathrm{x})$ and the vertical axis (y). So, the number of 400 square area is obtained. Each center point of the square is a candidate wind turbine location. The distance between candidate locations is selected as 4 rotor diameters of the wind turbine. There should be an acceptable distance between the turbines which is equal to at least 4 times of the turbine rotor diameter. The wake effect is significantly decreased above this distance. So, the wake effect is negligible of in this study. This map is transferred to the MATLAB environment. The average wind velocity MATLAB map is given at the Fig. 4.

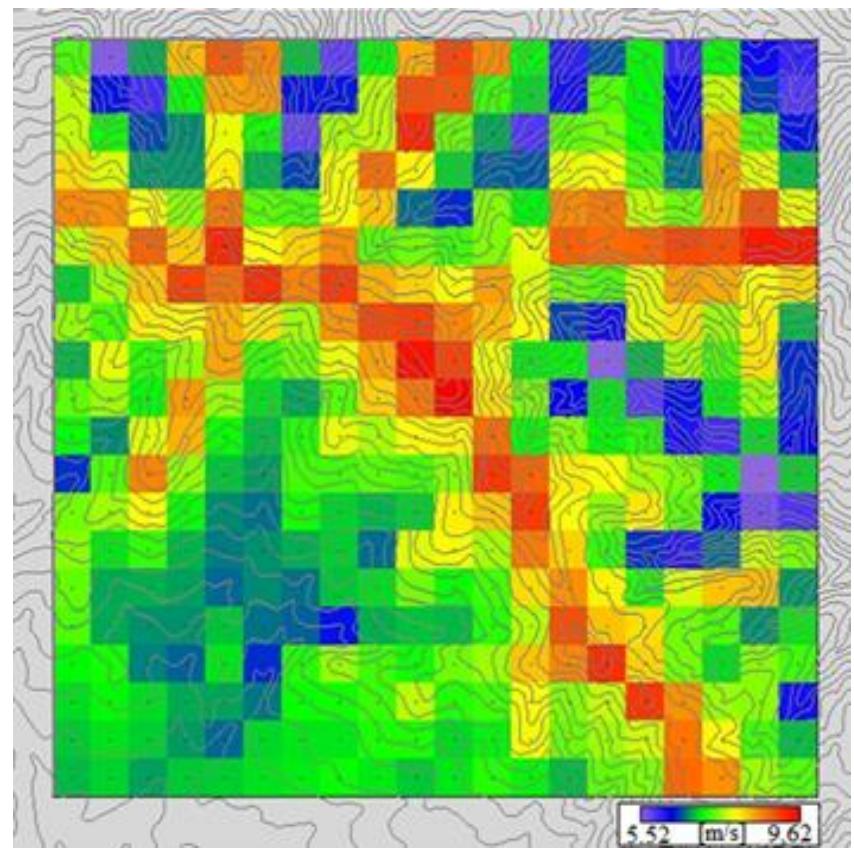

Figure 3. The average wind velocity map of WAsP

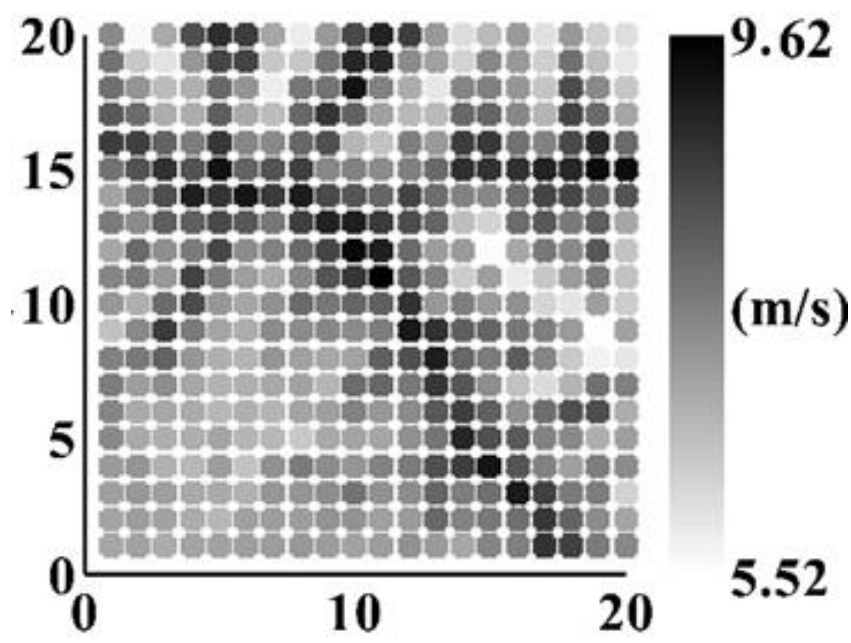

Figure 4. The average wind velocity map of MATLAB

In this model, the number of wind turbine is kept constant as equal to ten. Some characteristics of the wind turbine are summarized in Table 1.

Table 1. Wind turbine characteristics

\begin{tabular}{ll}
\hline Brand & Vestas \\
Model & V-63 \\
Hub height $(\mathrm{m})$ & 60 \\
Rotor diameter $(\mathrm{m})$ & 63 \\
Cut in wind speed $(\mathrm{m} / \mathrm{s})$ & 4 \\
Cut out wind speed $(\mathrm{m} / \mathrm{s})$ & 25 \\
\hline
\end{tabular}

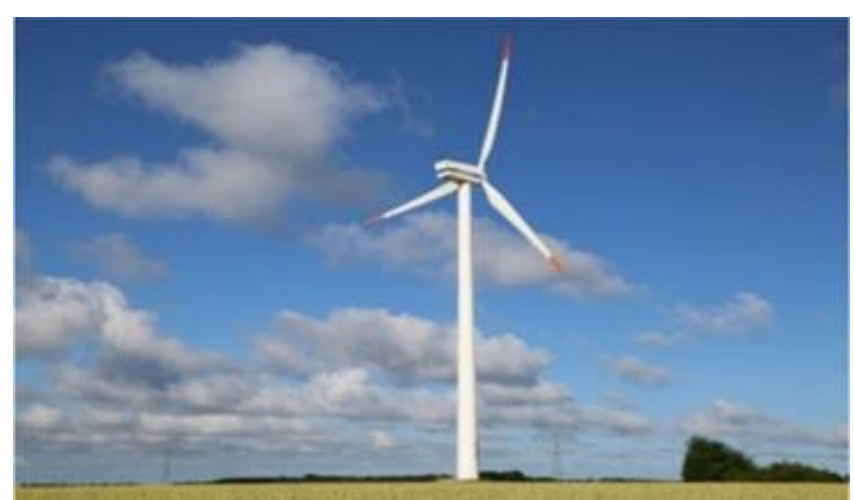

Figure 5. 1.5 MW wind turbine (Wind turbine model 2019)

General view of the turbine is as in Fig. 5. The nominal output power of each wind turbine is $1.5 \mathrm{MW}$.

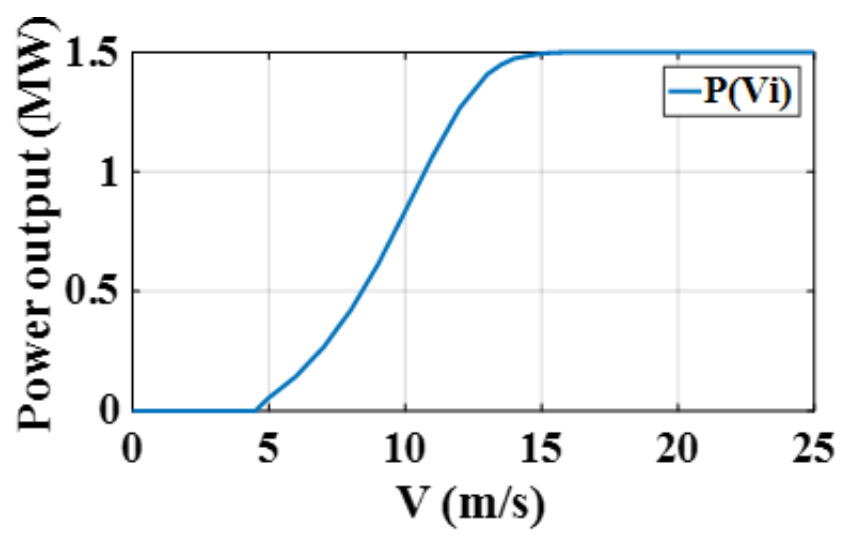

Figure 6. Wind turbine power curve 
The power curve of the wind turbine is given in Fig. 6. This figure shows the correlation between wind speed and power output.

\section{RESULTS}

The developed optimization model is solved by the PSO method and the optimal wind turbine locations are determined.. Objective function of this model is division of $\mathrm{C}_{\mathrm{wpp}}$ and $\mathrm{G}_{\mathrm{wpp}} . \mathrm{C}_{\mathrm{wpp}}$ is constant because number of the wind turbine is assumed to be 10 . So, the $G_{\text {wpp }}$ directly effects the objective function value.

Power generation of first local best solution is find out as $56957 \mathrm{kWh}$. The annual power generation increase by iteration number is given in Fig.7. The wind turbine positions are given in Fig. 8. Second local best solution value is $57949 \mathrm{KWh}$. The wind turbine positions of this solution are given in Fig. 9. The annual power generation increase by iteration during the second solution process are given in Fig.10.

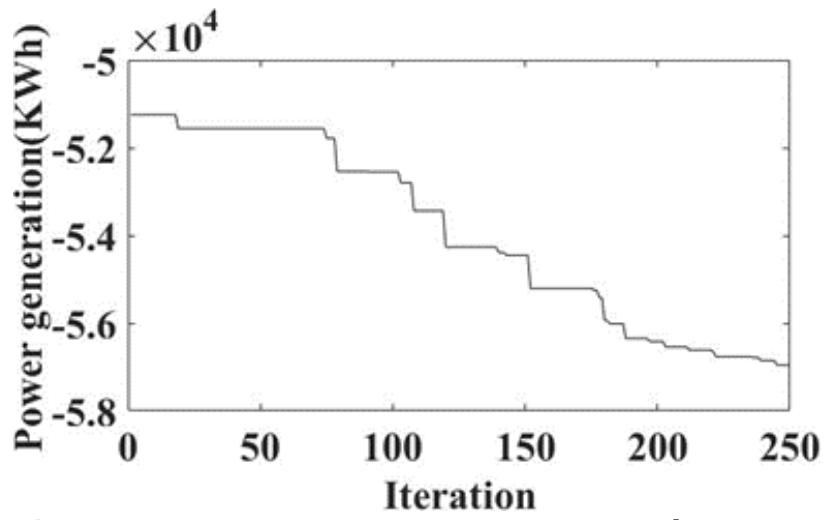

Figure 7. First power generation increase by iteration number

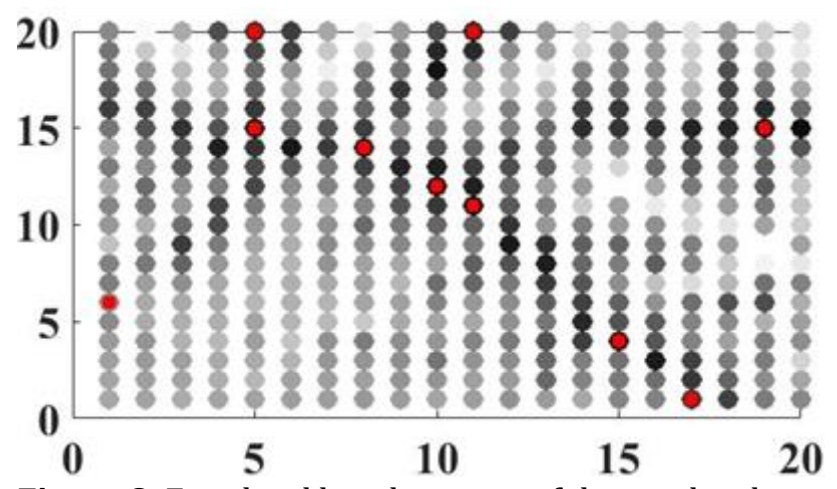

Figure 8. First local best locations of the wind turbines

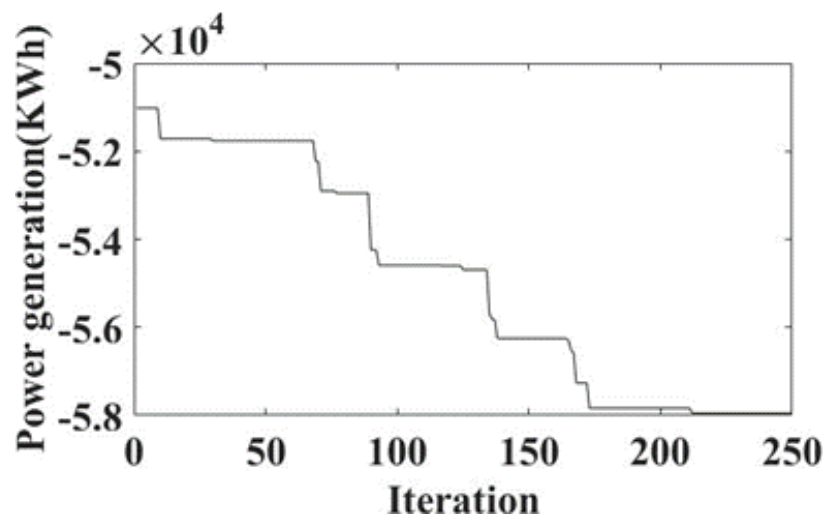

Figure 9. Second power generation increase by iteration number

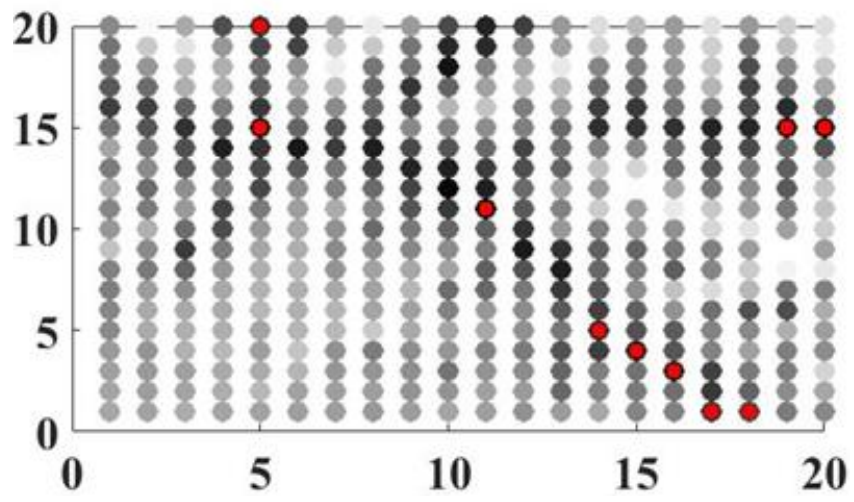

Figure 10. Second local best locations of the wind turbines

The global best power generation values for 150 populations and 250 iteration are shown in Fig. 7. Fig. 11. The optimal solution (wind turbine locations) are given in Table 2. The MATLAB model and WAsP power generation results for these locations are compared in Table 3. Also, the layout of the wind turbines in average wind speed map of WAsP software and MATLAB model are given in Fig.12. and Fig. 13. respectively.

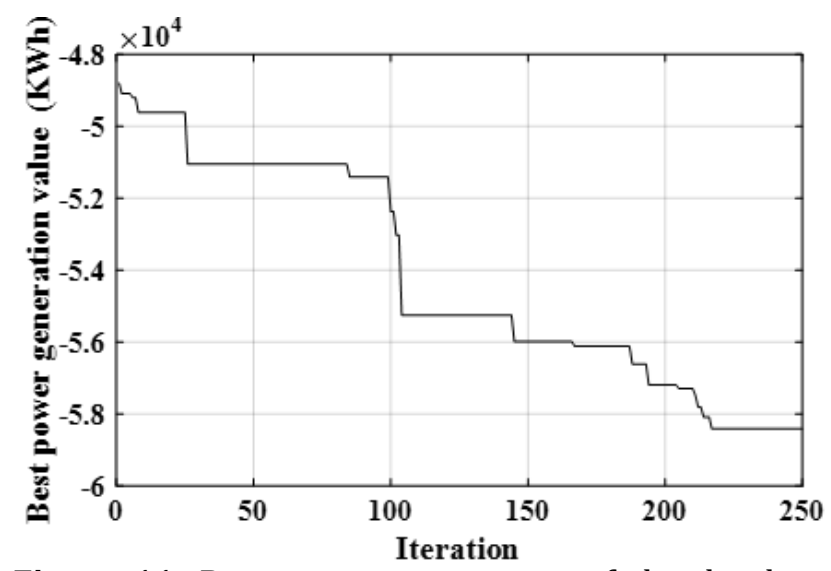

Figure 11. Best power generations of the developed model

Table 2. The locations of the wind turbines

\begin{tabular}{lllllllllll}
\hline Axis & T1 & T2 & T3 & T4 & T5 & T6 & T7 & T8 & T9 & T10 \\
\hline $\mathrm{y}$ & 16 & 15 & 12 & 18 & 11 & 5 & 4 & 3 & 1 & 15 \\
$\mathrm{x}$ & 1 & 5 & 10 & 10 & 11 & 14 & 15 & 16 & 17 & 20 \\
\hline
\end{tabular}

Table 3. The power generation results of the MATLAB model and WAsP model

\begin{tabular}{cccc}
\hline Turbine No & WASP(GWh) & MATLAB(GWh) & Error (\%) \\
\hline T1 & 5.125 & 5.152 & 0.52 \\
T2 & 5.977 & 5.968 & 0.15 \\
T3 & 6.184 & 6.205 & 0.34 \\
T4 & 6.002 & 6.012 & 0.16 \\
T5 & 6.296 & 6.272 & 0.38 \\
T6 & 5.883 & 5.883 & 0.00 \\
T7 & 5.737 & 5.764 & 0.47 \\
T8 & 5.650 & 5.630 & 0.35 \\
T9 & 5.498 & 5.471 & 0.49 \\
T10 & 6.041 & 6.063 & 0.36 \\
\hline Total & 58.393 & 58.420 & 0.04 \\
\hline
\end{tabular}




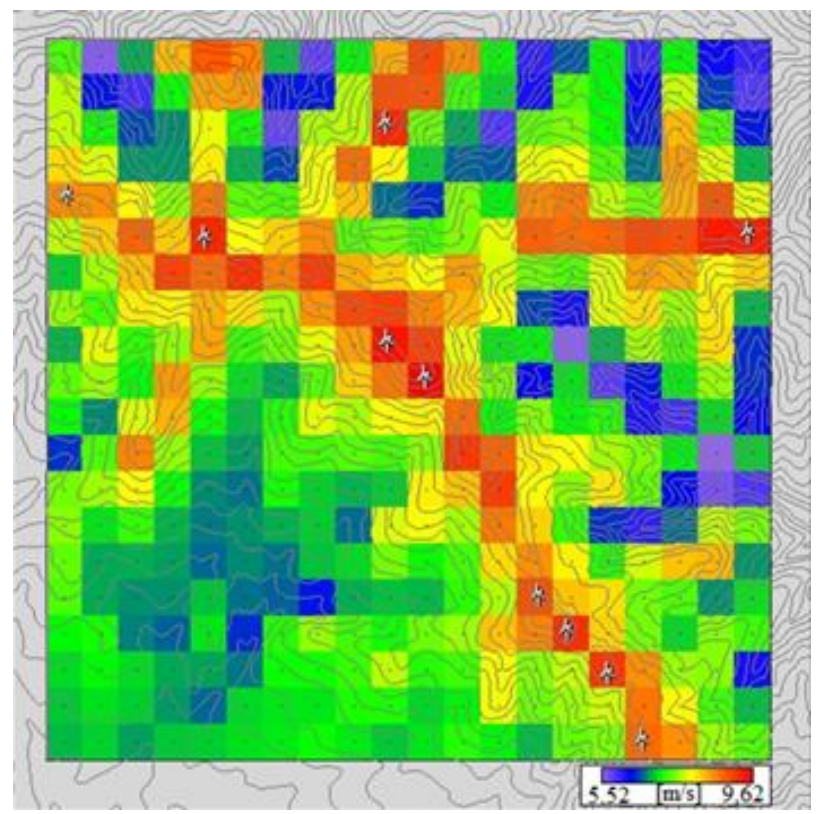

Figure 12. The layout of the wind turbines in average wind speed map of WAsP

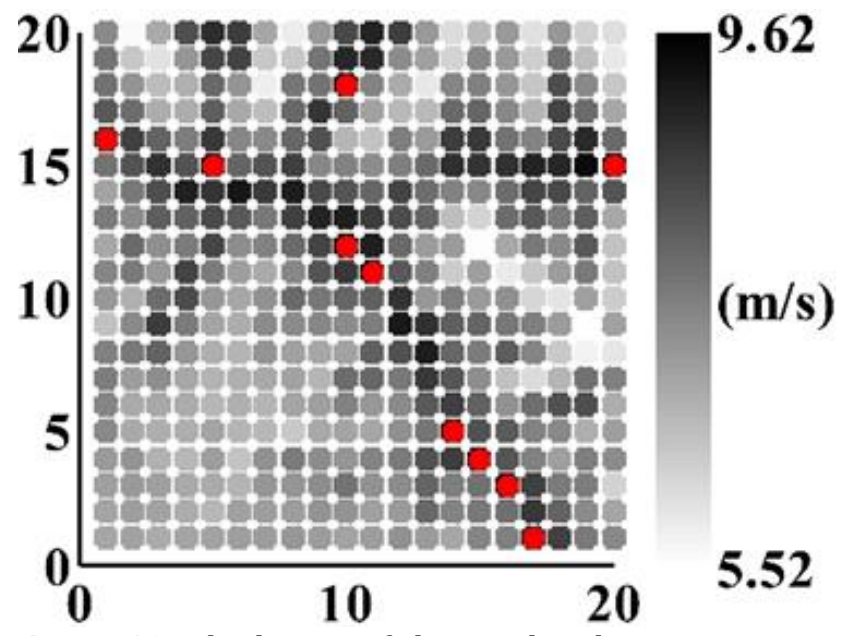

Figure 13. The layout of the wind turbines in average wind speed map of MATLAB model

\section{CONCLUSIONS}

Wind turbine location selection is one of the most important subjects in WPP installation. In this study, the effect of settlement locations on wind turbine power output is examined. A WPP layout model is developed based on the relationship between the wind turbine settlement locations and total power output. The PSO method is used to obtain optimal solutions. The optimal locations are shown in Fig. 12 and Fig. 13. In this study, the wake effect is neglected. But wake effect loss of the obtained locations is determined for different best solutions in WAsP. This loss is maximum $0.64 \%$. After that the global best solutions WAsP and MATLAB model results are compared in Table 3 . These results showed that developed MATLAB model can calculate the annual power generation of the wind turbines. The maximum error is $0.52 \%$. Also, there is a very small error $(0.04 \%)$ in total power generation. Furthermore, the PSO method has shown good performance in the developed optimization model for WPP installation.

In this study, 10 wind turbines are tried to be sited in 400 settlement locations. Thus, the solution space is small. If WPP installation optimization is performed at a wide range of area with many of the wind turbines, the solution space will be big. In this case, it is thought that the developed model will gain importance in the WPP installation. Besides, the wind turbine output power is calculated with small errors in the developed model. By this means, it is possible to solve this optimization problem in MATLAB environment with different optimization methods.

\section{REFERENCES}

Abdelsalam A M, El-Shorbagy M A (2018). Optimization of wind turbines siting in a wind farm using genetic algorithm based local search. Renewable Energy, 123, 748-755. DOI: 10.1016/j.renene.2018.02.083

Brusca S, Lanzafame R \& Messina M (2014). Wind turbine placement optimization by means of the Monte Carlo simulation method. Modelling and Simulation in $\quad$ Engineering, 760934 DOI: $10.1155 / 2014 / 760934$

Celik I, Yildiz C \& Sekkeli M (2018). An optimization model for wind turbine micro-siting in wind power plant installation. Gazi University Science Journal: PART:C Design and Technology, 6(4), 898-908. DOI: 10.29109/gujsc.424155

Celik I, Yildiz C \& Sekkeli M (2019). A model for evaluating the basic wake effect in the calculation of wind turbine power output on offshore wind power plant. The Black Sea Journal of Sciences, 9(1), 1-9. DOI: 10.31466/kfbd.531554 (in Turkish).

Changshui Z, Guangdong H \& Jun W (2011). A fast algorithm based on the sub- modular property for optimization of wind turbine positioning. Renewable Energy, 36(11), 2951-2958. DOI: 10.1016/j.renene.2011.03.045

Chen Y, Li H, Jin K, Song Q (2013). Wind farm layout optimization using genetic algorithm with different hub height wind turbines. Energy Conversion and Management, 70, 56-65. DOI: 10.1016/j.enconman.2013.02.007

Chen Y, Li H, He B \& Wang P (2015). Multi-objective genetic algorithm based innovative wind farm layout optimization method. Energy Conversion and Management, 105, 1318-1327. DOI: 10.1016/j.enconman.2015.09.011

Chen K, Song M X, Zhang X, Wang S F (2016). Wind turbine layout optimization with multiple hub height wind turbines using greedy algorithm. Renewable Energy, 96(A), 676-686. DOI: 10.1016/j.renene.2016.05.018

Emami A \& Noghreh P (2010). New approach on optimization in placement of wind turbines within wind farm by genetic algorithms. Renewable Energy, 35(7), 1559-1564. DOI: 10.1016/j.renene.2009.11.026

Engelbrecht A P (2005). Fundamentals of computational swarm intelligence. John Wiley \& Sons, United Kingdom.

Feng J \& Shen W Z (2015). Solving the wind farm layout optimization problem using random search algorithm. Renewable Energy, 78, 182-192. DOI: 10.1016/j.renene.2015.01.005 
Gao X, Yang H, Lu L \& Koo P (2015). Wind turbine layout optimization using multi- population genetic algorithm and a case study in Hong Kong offshore. Journal of Wind Engineering and Industrial Aerodynamics, 139, 89-99. DOI: 10.1016/j.jweia.2015.01.018

Garcia-Bustamante E, Gonzalez-Rouco J F, Jimenez P A, Navarro J \& Montávez J P (2009). A comparison of methodologies for monthly wind energy estimation. Wind Energy, 12, pp. 640-659. DOI: 10.1002/we.315

González J S, Rodriguez A G G, Mora J C, Payan M B \& Santos J R (2011). Overall design optimization of wind farms. Renewable Energy, 36(7), 1973-1982. DOI: $10.1016 /$ j.renene.2010.10.034

González J S, Rodriguez A G G, Mora J C, Santos J R, Payan M B (2010). Optimization of wind farm turbines layout using an evolutive algorithm. Renewable Energy, 35(8), 1671-1681. DOI: 10.1016/j.renene.2010.01.010

Grady S A, Hussaini M Y \& Abdullah M M (2005). Placement of wind turbines using genetic algorithms. Renewable Energy, 30(2), 259-270. DOI: 10.1016/j.renene.2004.05.007

Hou P, Hu W, Soltani M, Chen Z (2015). Optimized placement of wind turbines in large-scale offshore wind farm using particle swarm optimization algorithm. IEEE Transactions on Sustainable Energy, $6(4)$, 1272-1282. DOI: $10.1109 /$ TSTE.2015.2429912

Karadöl I, Keçecioğlu O F, Açıkgöz H \& Şekkeli M (2017). Examination of Solar and Wind Energy Hybrid System for Kahramanmaraş Region. KSU Journal of Engineering Sciences, 20(2), 89-96.

Kennedy J \& Eberhart R (1995). Particle Swarm Optimization. International Conference on Neural Networks, Perth, WA, Australia, 1942-1948. DOI: $10.1109 /$ ICNN.1995.488968

Kusiak A \& Song Z (2010). Design of wind farm layout for maximum wind energy capture. Renewable Energy, 35(3), 685-694. DOI: 10.1016/j.renene.2009.08.019

Long H \& Zhang Z (2015). A two-echelon wind farm layout planning model. IEEE Transactions on Sustainable Energy, 6(3), 863-871. DOI: $10.1109 /$ TSTE.2015.2415037

Marmidis G, Lazarou S \& Pyrgioti E (2008). Optimal placement of wind turbines in a wind park using Monte Carlo simulation. Renewable Energy, 33(7), 1455-1460. DOI: 10.1016/j.renene.2007.09.004

Mosetti G, Poloni C \& Diviacco B (1994). Optimization of wind turbine positioning in large windfarms by means of a genetic algorithm. Journal of Wind Engineering and Industrial Aerodynamics, 51(1), 105-116. DOI: 10.1016/0167-6105(94)90080-9

Pagnini L C, Burlando M, Repetto M P (2015). Experimental power curve of small-size wind turbines in turbulent urban environment. Apllied Energy, 154, 112-121. DOI: 10.1016/j.apenergy.2015.04.117
Parada L, Herrera C, Flores P \& Parada V (2017). Wind farm layout optimization using a Gaussian-based wake model. Renewable Energy, 107, 531-541. DOI: 10.1016/j.renene.2017.02.017

Pookpunt S \& Ongsakul W (2016). Design of optimal wind farm configuration using a binary particle swarm optimization at Huasai district, Southern Thailand. Energy Conversion and Management, 108, 160-180. DOI: 10.1016/j.enconman.2015.11.002

Pookpunt S \& Ongsakul W (2013). Optimal placement of wind turbines within wind farm using binary particle swarm optimization with timevarying acceleration coefficients. Renewable Energy, 55, 266-276. DOI: 10.1016/j.renene.2012.12.005

Sekkeli M, Keçecioğlu O F, Açıkgöz H \& Yıldız C (2015a). A comparison between theoretically calculated and actually generated electrical powers of wind turbines: A case study in Belen wind farm, Turkey. Academic Platform Journal of Engineering and Science, 1(3), 41-47. DOI: 10.5505/apjes.2013.55265

Sekkeli M, Yildiz C, Karik F, Sözen A (2015b). Wind energy in Turkey electricity market. Gazi Journal of Engineering Science, 1(2), 253-264.

Song M X, Chen K, Wang J (2018). Three-dimensional wind turbine positioning using Gaussian particle swarm optimization with differential evolution. Journal of Wind Engineering \& Industrial Aerodynamics, 172, 317-324. DOI: 10.1016/j.jweia.2017.10.032

Sun H, Yang H \& Gao X (2019). Investigation into spacing restriction and layout optimization of wind farm with multiple types of wind turbines. Energy, 168, 637-650. DOI: 10.1016/j.energy.2018.11.073

Turner S D O, Romero D A, Zhang P Y, Amon C H \& Chan T C Y (2014). A new mathematical programming approach to optimize wind farm layouts. Renewable Energy, 63, 674-680. DOI: 10.1016/j.renene.2013.10.023

Wang Y, Liu H, Long H, Zhang Z \& Yang S (2018). Differential evolution with a new encoding mechanism for optimizing wind farm layout. IEEE Transactions on Industrial Informatics, 14(3), 1040 1054. DOI: 10.1109/TII.2017.2743761

Wan C, Wang J, Yang G \& Zhang X (2010). Optimal micrositing of wind farms by particle swarm optimization. Advances in swarm intelligence. Springer, Berlin, Heidelberg. DOI: 10.1007/978-3-642-13495-1_25

Wind turbine model, https://en.wind-turbinemodels.com/turbines/821-vestas-v63 (Accessed 19 April 2019).

Yang K, Kwak G, Cho K, Huh J (2019). Wind farm layout optimization for wake effect uniformity. Energy, 183, 983-995. DOI: 10.1016/j.energy.2019.07.019

Yang J, Zhang R, Sun Q \& Zhang H (2015). Optimal wind turbines micrositing in onshore wind farms using fuzzy genetic algorithm. Mathematical Problems in Engineering, 1-9. 